\title{
An innovative approach to the topical treatment of acne
}

This article was published in the following Dove Press journal:

Clinical, Cosmetic and Investigational Dermatology

9 April 2015

Number of times this article has been viewed

\section{Adele Sparavigna \\ Beatrice Tenconi \\ Ileana De Ponti \\ Laura La Penna}

Dermlng srl, Clinical Research and Bioengineering Institute, Monza, MB, Italy
Correspondence: Adele Sparavigna Dermlng srl, Clinical Research and Bioengineering Institute, Viale Cesare Battisti 38, Monza, MB, Italy Tel +39039329666

Fax +39039 2329448

Email adele.sparavigna@derming.com
Abstract: Acne is characterized by primary lesions on the face, chest, and back, and by a variety of other signs and symptoms. In particular, acne inflammatory lesions result from Propionibacterium acnes colonization and are of particular relevance as they can cause permanent scarring. Acne also causes significant psychological morbidity in affected patients. Products currently available for the treatment of acne include systemic and topical treatments. As these products can cause severe side effects, new, innovative therapies are needed. Farmaka Acne Cream (FAC) is a novel, film-forming cream developed to treat mild and moderate acne. In vitro studies have demonstrated that FAC is as effective as 5\% benzoyl peroxide in inhibiting growth of $P$. acnes. In 32 subjects with mild or moderate acne, FAC reduced all the major signs and symptoms of the disease. These included itching, erythema, and scaling, as well as reductions in the numbers of papules, pustules, and open and closed comedones. Acne severity improved in $38 \%$ of subjects, while none worsened. FAC was found to be effective in controlling sebum secretion, and was non-comedogenic. Most subjects (90\%) reported tolerability as good or very good, while clinical efficacy and cosmetic acceptability were judged as good. For assessment of contact sensitization and photosensitization, FAC was applied daily to the backs of 29 subjects in two symmetric areas for 10 days. Using a solar stimulator, one minimal erythema dose was delivered to one side of the back from days 11 to 13 . The four different subareas of treated/ untreated and irradiated/nonirradiated and combinations thereof were compared. No cases of contact sensitization or photosensitization were observed, and FAC is considered safe for use in intense sunlight. In vitro and in vivo studies provide evidence for the safety and clinical benefits of FAC, a promising candidate for the treatment of mild and moderate acne.

Keywords: acne, Farmaka Acne Cream, Propionibacterium acnes

\section{Introduction}

Acne is characterized by primary lesions on the face, chest, and back, which form when the skin pores become clogged with oil, dead skin cells, and bacteria. Such lesions are either noninflammatory (open and closed comedones, also called whiteheads and blackheads) or inflammatory (papules and pustules). The inflammatory manifestations of acne result from Propionibacterium acnes colonization, and are of particular relevance as they can develop into nodules and cysts, potentially leading to permanent scarring. ${ }^{1}$ Acne severity is classified according to different scales. ${ }^{2}$ It is widely agreed, however, that the mild and moderate forms of acne display primary lesions only, while severe acne also includes nodules, cysts, and eventually open lesions. ${ }^{3}$ It is noteworthy that acne severity and scarring have been related to $P$. acnes inflammatory factors, ${ }^{4,5}$ bacterial growth metabolites such as allergens, toxins, or porphyrins, and enzymes. 
Acne is always accompanied by a variety of other signs and symptoms such as erythema, desquamation, burning, itching, dyschromia, and pain. Furthermore, acne causes significant psychological morbidity in affected patients. ${ }^{6}$

Acne is the most common skin disease, and although it usually manifests during puberty and worsens throughout adolescence, epidemiological studies suggest that it can arise at any age. Acne most frequently affects individuals between puberty and 30 years of age, with $79 \%-95 \%$ of subjects aged between 16 years and 18 years ${ }^{7}$ and $80 \%$ of subjects between puberty and 30 years of age. ${ }^{8}$ Acne is also reported in younger children, with $28 \%-61 \%$ of children aged between 10 years and 12 years being affected. ${ }^{9}$ The condition has even been reported in children as young as 4-7 years. ${ }^{10-12}$ The exact cause of acne is still unknown, and although early $P$. acnes colonization has an important role in the disease, the triggers of acne and the effect of treatment on the course of the disease remain unclear. ${ }^{4}$ Four contributing pathogenic factors of acne have, however, been clearly identified: $P$. acnes colonization of the pilosebaceous unit, inflammation, seborrhea, and follicular desquamation (hyperkeratosis). ${ }^{13}$ Secondary factors that could trigger or exacerbate acne may include, among others, inappropriate personal hygiene (use of abrasive soaps, harsh detergents, and excessive scrubbing), use of cosmetics and emollients (pore occlusion could cause an acneiform eruption), environmental factors (exposure to dust, dirt, polluting elements, food residues, and sweat), ${ }^{11,14-16}$ high body mass index, ${ }^{17,18}$ and common medications. ${ }^{19}$ The skin's acid mantle is fundamental to barrier formation and cutaneous antimicrobial defense, and exogenous factors such as detergents, cosmetic products, occlusive dressings, and topical antibiotics could play a role in the pathogenesis of acne by influencing skin $\mathrm{pH}^{20,21}$ Acne can therefore be considered a multifactorial disease, ${ }^{22-25}$ and although $P$. acnes is widely concluded to cause this disease and is thus the main target of most therapeutic protocols, ${ }^{26}$ defining a standard treatment regimen is still a great challenge to researchers. ${ }^{27}$ Currently, acne can be controlled with appropriate treatment, ${ }^{1}$ although improvements may take up to several months, and usually vanish when treatment is withdrawn. Furthermore, spontaneous improvement might also occur over time.

\section{Issues in the current management of acne}

As for other multifactorial diseases, a variety of different products, primarily pharmaceuticals, can be used to treat acne. Although topical preparations are most frequently used, systemic drugs are also indicated for severe acne.
Currently available systemic products include the retinoid isotretinoin, antibiotics, or oral contraceptives, all of which are indicated for more severe acne, acne resistant to other therapies, and nodulocystic, scarring acne. Although the mechanism of action of retinoids is still unclear, ${ }^{28}$ oral isotretinoin is considered the most effective medication available to date. ${ }^{27}$ Treatment with isotretinoin, however, is associated with the most serious side effects elicited by acne treatments, including exacerbation of acne, teratogenicity, and permanent side effects, a toll which is gradually restricting its regulation ${ }^{29,30}$ and use. ${ }^{31}$ Oral antibiotics are usually preferred for the treatment of acne located on the trunk, acne unresponsive to topical therapy, and in patients at a greater risk of scarring. Antibiotics effectively reduce the number of inflammatory lesions but do not completely clear the condition. Moreover, worldwide concern over the increasing resistance of $P$. acnes to erythromycin has prompted questions regarding the use of antibiotics for acne. ${ }^{32,33}$ Oral contraceptive preparations are combinations of estrogens and progestogens that work by suppressing sebaceous gland activity and decreasing androgen secretion. While hormonal therapies are considered an excellent choice for women who need oral contraception, ${ }^{34}$ it is not clear how they compare with alternative acne treatments. ${ }^{35}$

Topical preparations comprise retinoids and antibiotics, as well as many other active ingredients (mainly salicylic acid, azelaic acid, and benzoyl peroxide). Among topical preparations, combination products are increasingly popular, for example, retinoid and antibiotic, retinoid and zinc, retinoid and benzoyl peroxide, benzoyl peroxide and antibiotic, or benzoyl peroxide and antiseptic. Single-agent benzoyl peroxide preparations are, however, considered the gold standard for safety and efficacy in topical acne treatment. ${ }^{36}$ Benzoyl peroxide kills $P$. acnes by the generation and release of oxygen free radicals, ${ }^{37,38}$ while seborrhea remains unaffected (as for topical retinoids). ${ }^{39}$ Single-agent benzoyl peroxide preparations have demonstrated greater activity against inflammatory lesions than topical isotretinoin, ${ }^{40,41}$ and have proven as effective as a topical combination therapy of benzoyl peroxide and an antibiotic for people with mild-to-moderate facial acne. ${ }^{42}$ Further investigations are, however, required, since previous studies have suggested that some combinations with benzoyl peroxide (ie, with clindamycin ${ }^{43}$ or retinoic acid ${ }^{44}$ ) are superior to single-agent therapy. Unfortunately, benzoyl peroxide causes primary irritant dermatitis (erythema, dryness, desquamation, burning, and itching), and patients are advised to expect this side effect, and to discontinue therapy if it becomes severe. ${ }^{45}$ Low-percentage benzoyl peroxide 
preparations $(2.5 \%-5 \%)$ are less irritating, and furthermore, there is no clear evidence that stronger preparations are more effective. ${ }^{46}$ Other common topical agents include sulfur, resorcinol, sulfacetamide, aluminum, and zinc; however, data from peer-reviewed literature suggest that these agents have only limited efficacy. ${ }^{47}$ Finally, current comparative evidence does not clearly support the use of topical dapsone 4 and taurine bromamine ${ }^{48}$ for the treatment of acne.

Although acne is widespread with numerous treatment options available, ${ }^{49}$ the condition is still not considered curable, prompting further investigation by the pharmaceutical industry. All mainstream products can cause severe side effects including, paradoxically, the typical signs and symptoms of acne, and there is therefore a demand for new innovative treatments.

\section{Mode of action of Farmaka Acne Cream}

The primary role of the skin's acid mantle ( $\mathrm{pH} 4.5-5.5)$ in barrier functionality, lipid synthesis, and in the direct and indirect regulation of microbiome is widely acknowledged. ${ }^{50-52}$ Alkaline cosmetics, detergents, ${ }^{50-52}$ and also topical drugs including acne treatments ${ }^{53}$ are thought to favor the onset or exacerbation of several different dermatological conditions, including acne. Farmaka Acne Cream (FAC) is a novel topical formulation developed to combat the signs of mild and moderate acne. FAC forms a layer of $\mathrm{pH} 4.0$ on the skin, and thus creates a superficial acidic milieu, targeting both primary and secondary acne factors. Its principal effects include the following:

1. inhibition of $P$. acnes growth and metabolism;

2. restoration and maintenance of the skin's acid mantle, barrier functionality, and moisture balance, thus contributing to the mitigation of acne signs and symptoms and potentially of the most common side effects of mainstream treatments.

FAC's superficial film physically protects skin from dust, dirt, polluting elements, food residues, and sweat, the secondary factors that could trigger or exacerbate acne. ${ }^{11}$ FAC is well tolerated, non-comedogenic, safe for ultraviolet exposure, perfume-free, and preservative- and paraben-free, and would appear to be a promising candidate for the adjuvant treatment of mild and moderate acne.

Notably, FAC's film-forming ingredient is a polyol polymer. These chemicals are widely used in the pharmaceutical and cosmetic industry for their emollient and moisturizing properties. ${ }^{54}$ They have also been thoroughly investigated as vehicles for the active principles in topical acne treatments, with reports of significant reductions in side effects such as irritation, dry skin, and desquamation but with no effect on overall efficacy. ${ }^{55-61}$ FAC's beneficial effect on the skin's barrier functionality and moisture balance could also mitigate the main signs and symptoms of acne such as erythema, desquamation, burning, itching, dyschromia, and pain. As these manifestations of acne are also the most common side effects of the mainstream treatments, FAC could eventually complement their use, possibly reducing their adverse reactions and thus increasing patient compliance and overall therapeutic efficacy.

\section{Preclinical efficacy of FAC}

Acne severity and scarring have been linked to $P$. acnes inflammatory factors. ${ }^{4,5}$ In particular, porphyrin concentration has been related to acne severity, ${ }^{62}$ while enzymes such as phosphatases, proteinases, lipases, and hyaluronate lyase are known to participate in scarring. Like other bacteria, P. acnes growth and metabolism are highly $\mathrm{pH}$ dependent. Growth was reported to be greater in a $\mathrm{pH}$ range of 6.0-7.0 than in a more acidic milieu, ${ }^{63}$ was promoted at $\mathrm{pH}$ values of 6.0 and 6.5 , and was optimal at $\mathrm{pH} 6.7 .{ }^{64}$ Moreover, maximum specific growth rates and optimum biomass production for $P$. acnes were both measured at $\mathrm{pH} 6.0 .{ }^{65}$ Conversely, growth was inhibited at $\mathrm{pH}$ values of 5.0 and $5.5,{ }^{66}$ and no growth was observed at $\mathrm{pH} 4.0 .{ }^{63}$ The secretion of metabolites, phosphatase, and proteinase was completely inhibited at $\mathrm{pH} 4.0$, while the secretion of lipase and hyaluronate lyase was inhibited at $\mathrm{pH}$ 4.5. ${ }^{63}$ Additionally, porphyrin concentration was reported to be three times higher at $\mathrm{pH} 6.1$ than $5.3 .{ }^{67}$

FAC has been formulated at $\mathrm{pH} 4.0$ to enable optimal inhibition of $P$. acnes growth and metabolism. To investigate the beneficial effects of FAC, a proof-of-concept experiment was conducted in which the product was tested in vitro on cultures of $P$. acnes versus gold standard 5\% benzoyl peroxide, the market leader brand. Both preparations caused a reduction of $>3 \log$ of the number of microorganisms after 6 hours of contact time (Table 1). ${ }^{68}$ These data demonstrated that FAC is as effective as the active comparator in inhibiting or impeding bacterial growth. The inhibition of $P$. acnes growth and metabolism by FAC could be related to the creation of a superficial acidic milieu, as well as restoration of the skin's acid mantle and commensal microbiome.

\section{Efficacy and tolerability}

As acne is always accompanied by erythema, desquamation, burning, itching, dyschromia, and pain, the efficacy and tolerability of FAC, an acidic product, were investigated clinically. 
Table I Log reduction in growth of Propionibacterium acnes

\begin{tabular}{llll}
\hline $\begin{array}{l}\text { Contact } \\
\text { time (hours) }\end{array}$ & $\begin{array}{l}\text { FAC log } \\
\text { reduction }\end{array}$ & $\begin{array}{l}\text { BP 5\% log } \\
\text { reduction }\end{array}$ & $\begin{array}{l}\text { Control log } \\
\text { reduction }\end{array}$ \\
\hline 0 & 0.06 & 0.04 & 0.06 \\
3 & 2.59 & 2.83 & 0.02 \\
6 & $>3.87$ & $>3.87$ & -0.02 \\
12 & $>3.87$ & $>3.87$ & 0.24 \\
24 & $>3.87$ & $>3.87$ & 0.93 \\
\hline
\end{tabular}

Abbreviations: BP, $5 \%$ benzoyl peroxide; FAC, Farmaka Acne Cream.

Initial testing was conducted in an open study of 32 subjects with mild or moderate acne on the face. ${ }^{25}$ FAC was applied to the face, and to the left and right side of the suprascapular region of the back. Subjects were examined prior to the first-product application, and after 4 weeks of twice-daily treatment. Efficacy was evaluated clinically in terms of the reduction of acne signs and symptoms (ie, erythema, scaling, number of open and closed comedones, papules, pustules, dyschromia, pain, burning, and itching). Additional assessments included follicular biopsy and morphometric analysis of sebum and photographic evaluation. Photographs were taken of the areas of acne in each subject prior to and at the end of treatment with FAC. For analysis of the comedolytic activity of FAC, follicular biopsies were performed in each subject. Samples of the cutaneous surface under investigation were taken by stripping an area of skin $(5 \mathrm{~cm} \times 5 \mathrm{~cm})$ at baseline and at the end of the treatment period. The follicular biopsy was therefore a cast of the follicular infundibulus with associated hair and keratinic material. In acneic skin or skin prone to acne, an increase in keratinic material can result in the formation of microcomedones, and eventually, clinically evident comedones. Statistical analyses of the density and total area of the comedones were performed using Student's $t$-test or nonparametric tests. For analysis of sebum prior to and after treatment, Sebutape ${ }^{\circledR}$ (Cu-Derm Corp, Dallas, TX, USA) was applied to the skin for 60 minutes to enable the collection of sebum drops arising from the cutaneous surface. Computerized morphometric analysis of the sebum spots was used to determine the ratio of the surface covered by
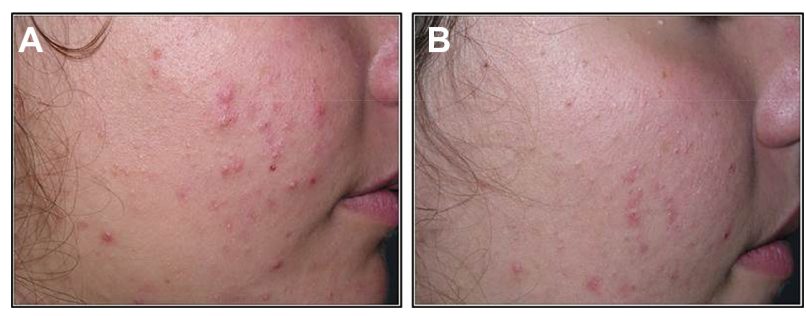

Figure I Photographic evaluation of Farmaka Acne Cream in volunteer I. Notes: (A) Before treatment. (B) After 4 weeks of treatment.
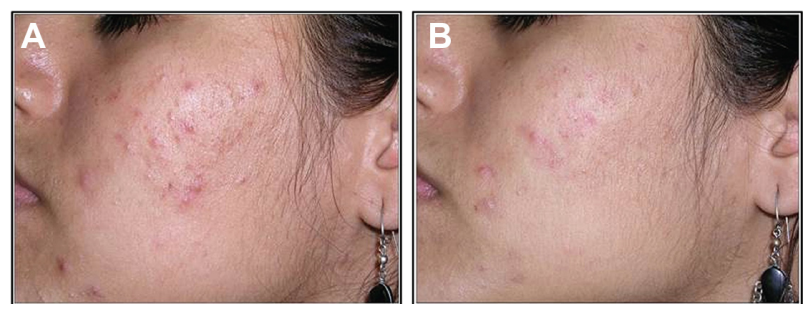

Figure 2 Photographic evaluation of Farmaka Acne Cream in volunteer 27. Notes: (A) Before treatment. (B) After 4 weeks of treatment.

sebum and total surface area of the specimen and the mean dimensions of the sebum spots, that is, the area, diameter, and major and minor axes. Image analysis was performed on samples of the same area of the cutis using a stereomicroscope connected to an analogical video camera. Subjects were asked to judge the product's efficacy, tolerability, and cosmetic acceptability.

Clinical data demonstrated that treatment with FAC reduced all of the major signs and symptoms of acne including itching, erythema, and scaling, with $38 \%, 86 \%$, and $76 \%$ of subjects, respectively, showing significant improvement in these symptoms and none experiencing worsening. Additionally, reductions in the numbers of papules $(-52 \%)$, pustules (-41\%) (Figures 1 and 2), and open and closed comedones ( $-48 \%$ and $-45 \%$, respectively) were observed. Overall, acne severity was clearly improved in $38 \%$ of the subjects, while none worsened. Furthermore, FAC was also found to be effective in controlling sebum secretion (Figures 3 and 4), and was non-comedogenic. Finally, 90\% of subjects judged tolerability as good or very good, while clinical efficacy and cosmetic acceptability were both judged good. The authors reported an overall improvement of acne in $76 \%$ of subjects, and proposed that FAC should be considered a valid adjuvant for the treatment of acne. ${ }^{25}$ In a subsequent study, FAC was tested for contact sensitization and photosensitization, two common side effects of mainstream acne treatments, on 29 subjects affected by mild or moderate facial acne. ${ }^{69}$ FAC was applied to two symmetric
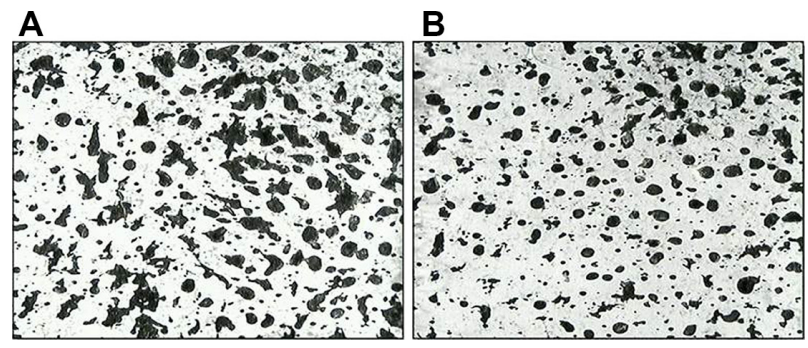

Figure 3 Sebutape of volunteer 4.

Notes: (A) Before treatment. (B) After 4 weeks of treatment. 

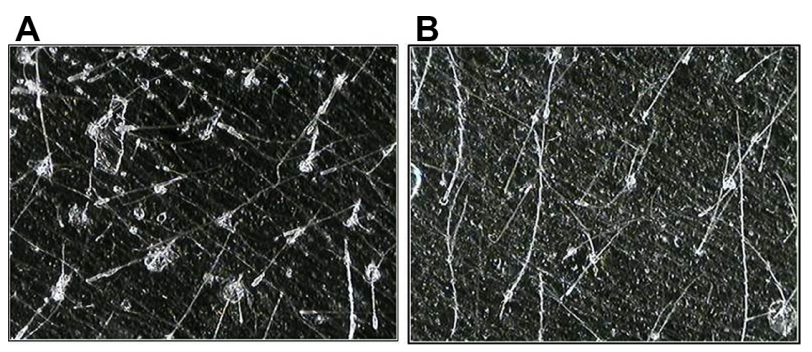

Figure 4 Follicular biopsy in volunteer 16.

Notes: (A) Before treatment. (B) After 4 weeks of treatment.

areas of each subject's back daily for 10 days. One minimal erythema dose was delivered to one side of the back using a solar stimulator, beginning on day 11 and continued for the next 2 consecutive days (ie, 3 days in total). Thus, four different subareas of treated/untreated and irradiated/ nonirradiated and combinations thereof were created. Two skin areas were designated as controls: one area to which FAC was applied but not irradiated in order to determine whether contact sensitization could be linked exclusively to FAC, and another area irradiated for 3 consecutive days but without application of FAC. This second control area was intended to identify possible idiopathic reactions to solar irradiation. Clinical features of contact sensitization or photosensitization (erythema, itching, blistering, edema, and scaling) were assessed according to a three-point scale $(0=$ absent; $1=$ mild; $2=$ moderate; $3=$ intense $)$. No reports of contact sensitization or photosensitization were observed in the treated and nonirradiated areas. The author concluded that FAC should be considered safe for use in intense sunlight. ${ }^{69}$

\section{Conclusion}

Despite being widespread with a large number of treatment options, acne is not considered curable. Moreover, mainstream treatments for acne can cause side effects, some of which are severe. FAC is an innovative film-forming cream with a synergetic mode of action that inhibits $P$. acnes proliferation, restores the skin's acid mantle and barrier functionality, and provides physical protection from acne secondary factors. In vitro and in vivo studies provide an initial body of evidence on the safety and clinical benefits of FAC, a promising candidate for the treatment of mild and moderate acne.

\section{Acknowledgments}

Insight Medical Writing (Kidlington, UK) assisted in the preparation of this manuscript. This review was funded by Farmaka srl (Milan, Italy).

\section{Disclosure}

This review was funded by Farmaka srl, the inventor, proprietor, and manufacturer of the tested product "Farmaka Acne Cream". The authors have no other disclosures or conflicts of interest to declare.

\section{References}

1. The Gale Group. Gale Encyclopedia of Medicine. 3rd ed. Michigan The Gale Group; 2011.

2. Adityan B, Kumari R, Thappa DM. Scoring systems in acne vulgaris. Indian J Dermatol Venereol Leprol. 2009;75(3):323-326.

3. Pochi PE, Shalita AR, Strauss JS, et al. Report of the consensus conference on acne classification. J Am Acad Dermatol. 1991;24(3): 495-500.

4. Stotland M, Shalita AR, Kissling RF. Dapsone 5\% gel: a review of its efficacy and safety in the treatment of acne vulgaris. Am J Clin Dermatol. 2009;10(4):221-227.

5. Borelli C, Merk K, Schaller M, et al. In vivo porphyrin production by $P$. acnes in untreated acne patients and its modulation by acne treatment. Acta Derm Venereol. 2006;86(4):316-319.

6. Williams HC, Dellavalle RP, Garner S. Acne vulgaris. Lancet. 2012;379(9813):361-372.

7. Cordain L, Lindeberg S, Hurtado M, Hill K, Eaton Bbrand-Miller J. Acne vulgaris: a disease of western civilization. Arch Dermatol. 2002;138:1584-1590.

8. Cunliffe WJ, Gould DJ. Prevalence of facial acne vulgaris in late adolescence and in adults. Br Med J. 1979;1:1109-1110.

9. Kubba R, Bajaj AK, Thappa DM, et al. Epidemiology of acne. Indian J Dermatol Venereol Leprol. 2009;75(7):3.

10. Rademaker M, Garioch JJ, Simpson NB. Acne in schoolchildren: no longer a concern for dermatologists. BMJ. 1989;298(6682):1217-1219.

11. Kilkenny M, Merlin K, Plunkett A, Marks R. The prevalence of common skin conditions in Australian school children, III: Acne vulgaris. Br J Dermatol. 1998;139(5):840-845.

12. Lello J, Pearl A, Arroll B, Yallop J, Birchall NM. Prevalence of acne vulgaris in Auckland senior high school students. $N Z$ Med J. 1995;108(1004):287-289.

13. Feldman S, Careccia RE, Barham KL, Hancox J. Diagnosis and treatment of acne. Am Fam Physician. 2004;69(9):2123-2130.

14. Andrew FA, Lamb A. Concomitant therapy for acne in patients with skin of color: a case-based approach. Dermatol Nurs. 2009;21:1.

15. Thiboutot D, Gollnick H, Bettoli V, et al; Global Alliance to Improve Outcomes in Acne. Global alliance to improve outcomes in acne. New insights into the management of acne: an update from the Global Alliance to Improve Outcomes in Acne group. $J$ Am Acad Dermatol. 2009;60(5 Suppl):S1-S50.

16. Toyoda M, Morohashi M. Pathogenesis of acne. Med Electron Microsc. 2001;34(1):29-40.

17. Tsai MC, Chen W, Cheng YW, Wang CY, Chen GY, Hsu TJ. Higher body mass index is a significant risk factor for acne formation in schoolchildren. Eur J Dermatol. 2006;16(3):251-253.

18. Halvorsen JA, Vleugels RA, Bjertness E, Lien L. A population-based study of acne and body mass index in adolescents. Arch Dermatol. 2012;148(1):131-132.

19. Zaenglein AL, Thiboutot DM. Acne vulgaris. In: Bolognia JL, Jorizzo JL, Rapini RP, editors. Dermatology. New York: Mosby; 2003: 533-534.

20. Clubdermaweb. Secondary Acne. Dermatology Practical Sheets; 2011. Available from: http://assets.clubdermaweb.com/mediastore/practicalsheets/2/b/581054be.pdf. Accessed September 17, 2014.

21. Singh S, Mann BK, Tiwary NK. Acne cosmetica revisited: a case-control study shows a dose-dependent inverse association between overall cosmetic use and post-adolescent acne. Dermatology. 2013;226(4): $337-341$. 
22. Well D. Acne vulgaris: a review of causes and treatment options. Nurse Pract. 2013;38(10):22-31.

23. Selway J. Case review in adolescent acne: multifactorial considerations to optimizing management. Dermatol Nurs. 2010;22:1.

24. Ganceviciene R, Böhm M, Fimmel S, Zouboulis CC. The role of neuropeptides in the multifactorial pathogenesis of acne vulgaris. Dermatoendocrinology. 2009;1(3):170-176.

25. Sparavigna A, Setaro M, Sormani S, Bergamaschi M. Dermatological and instrumental evaluation of the activity of a new dermocosmetic product adjuvant in the treatment of acne. Giornale Italiano di Dermatologia e Venereologia. 2006;141(5):439-448.

26. Mayo Clinic. Over-the-Counter Acne Products: What Works and Why; 2012. Available from: http://www.mayoclinic.org/diseases-conditions/ acne/in-depth/acne-products/art-20045814. Accessed September 17, 2014.

27. Ramos-e-Silva M, Carneiro SC. Acne vulgaris: review and guidelines. Dermatol Nurs. 2009;21(2):63-68. [quiz 69].

28. Crettaz M, Baron A, Siegenthaler G, Hunziker W. Ligand specificities of recombinant retinoic acid receptors RAR alpha and RAR beta. Biochem J. 1990;272(2):391-397.

29. Isotretinoin (marketed as Accutane) Capsule Information. United States Food and Drug Administration; 2010. Available from: http:// www.fda.gov/Drugs/DrugSafety/PostmarketDrugSafetyInformationfor PatientsandProviders/ucm094305.htm. Accessed September 17, 2014.

30. Lowenstein EJ. Isotretinoin made SMART and simple. Cutis. 2002;70(2):115-120.

31. Rosenmeier GJ, Torok HM. iPLEDGE and its implementation in Dermatology practices. Cos Dermatol. 2013:6-8.

32. Eady AE, Cove JH, Layton AM. Is antibiotic resistance in cutaneous propionibacteria clinically relevant? Implications of resistance for acne patients and prescribers. Am J Clin Dermatol. 2003;4(12): 813-831.

33. Simonart T, Dramaix M. Treatment of acne with topical antibiotics: lessons from clinical studies. Br J Dermatol. 2005;153(2): 395-403.

34. Gollnick H, Cunliffe W, Berson D, et al; Global Alliance to Improve Outcomes in Acne. Management of acne: a report from a global alliance to improve outcomes in acne. J Am Acad Dermatol. 2003;49(1 Suppl): $\mathrm{S} 1-\mathrm{S} 37$.

35. Arowojolu AO, Gallo MF, Lopez LM, Grimes DA, Garner SE. Combined oral contraceptive pills for treatment of acne. Cochrane Database Syst Rev. 2009;3:CD004425.

36. Food and Drug Administration, HHS. Classification of benzoyl peroxide as safe and effective and revision of labelling to drug facts format; topical acne drug products for over-the-counter human use; final rule. Fed Regist. 2010;75:9767-9777.

37. Bojar RA, Cunliffe WJ, Holland KT. The short-term treatment of acne vulgaris with benzyl peroxide: effects on the surface and follicular cutaneous microflora. Br J Dermatol. 1995;132(2):204-208.

38. Haider A, Shaw JC. Treatment of acne vulgaris. JAMA. 2004;292(6): 726-735.

39. Goldstein JA, Pochi PE. Failure of benzoyl peroxide to decrease sebaceous gland secretion in acne. Dermatologica. 1981;162(4): 287-291.

40. Lyons RE. Comparative effectiveness of benzoyl peroxide and tretinoin in acne vulgaris. Int J Dermatol. 1978;17(3):246-251.

41. Hughes BR, Norris JF, Cunliffe WJ. A double-blind evaluation of topical isotretinoin $0.05 \%$, benzoyl peroxide gel $5 \%$ and placebo in patients with acne. Clin Exp Dermatol. 1992;17(3):165-168.

42. Ozolins M, Eady EA, Avery AJ, et al. Comparison of five antimicrobial regimens for treatment of mild to moderate inflammatory facial acne vulgaris in the community: randomized controlled trial. Lancet. 2004;364(9452):2188-2195.

43. Seidler EM, Kimball AB. Meta-analysis comparing efficacy of benzoyl peroxide, clindamycin, benzoyl peroxide with salicylic acid, and combination benzoyl peroxide/clindamycin in acne. J Am Acad Dermatol. 2010;63(1):52-62.
44. Handojo I. Retinoic acid cream (Airol cream) and benzoyl-peroxide in the treatment of acne vulgaris. Southeast Asian J Trop Med Public Health. 1979;10(4):548-551.

45. Benzac ${ }^{\circledR}$ AC. Prescribing Information. Galderma Laboratories, L.P: Texas, USA; 2004. Available from: http://www.galdermausa.com/PI/ BenzacACPI.pdf. Accessed September 17, 2014.

46. Fakhouri T, Yentzer BA, Feldman SR. Advancement in benzoyl peroxidebased acne treatment: methods to increase both efficacy and tolerability. J Drugs Dermatol. 2009;8(7):657-661.

47. Strauss JS, Krowchuk DP, Leyden JJ, et al; American Academy of Dermatology/American Academy of Dermatology Association. Guidelines of care for acne vulgaris management. J Am Acad Dermatol. 2007;56(4):651-663.

48. Farrar MD, Ingham E. Acne: inflammation. Clin Dermatol. 2004;22(5): 380-384.

49. Lehmann HP, Andrews JS, Robinson KA, Holloway VL, Goodman SN. Management of Acne. US Agency for Healthcare Research and Quality (AHRQ) Evidence Report/Technology; 2001. [Assessment Number 17].

50. Schmid MH, Korting HC. The concept of the acid mantle of the skin: its relevance for the choice of skin cleansers. Dermatology. 1995;191(4): 276-280.

51. Korting HC, Hübner K, Greiner K, Hamm G, Braun-Falco O. Differences in the skin surface $\mathrm{pH}$ and bacterial microflora due to the long-term application of synthetic detergent preparations of $\mathrm{pH} 5.5$ and $\mathrm{pH}$ 7.0. Results of a crossover trial in healthy volunteers. Acta Derm Venereol. 1990;70(5):429-431.

52. Mauro T, Holleran WM, Grayson S, et al. Barrier recovery is impeded at neutral $\mathrm{pH}$, independent of ionic effects: implications for extracellular lipid processing. Arch Dermatol Res. 1998;290(4):215-222. [Erratum in: Arch Dermatol Res. 1998;290(7):405].

53. Korting HC, Kerscher M, Schäfer-Korting M, Berchtenbreiter U. Influence of topical erythromycin preparations for acne vulgaris on skin surface pH. Clin Investig. 1993;71(8):644-648.

54. European Commission, Cosmetics - CosIng. PPG-12/SMDI Copolymer; 2014. Available from: http://ec.europa.eu/consumers/cosmetics/ cosing/index.cfm?fuseaction $=$ search.details\&id=79844. Accessed September 17, 2014.

55. Lucky AW, Cullen SI, Funicella T, Jarratt MT, Jones T, Reddick ME. Double-blind, vehicle-controlled, multicenter comparison of two $0.025 \%$ tretinoin creams in patients with acne vulgaris. $\mathrm{J} \mathrm{Am} \mathrm{Acad}$ Dermatol. 1998;38(4):S24-S30.

56. Lucky AW, Cullen SI, Jarratt MT, Quigley JW. Comparative efficacy and safety of two $0.025 \%$ tretinoin gels: results from a multicenter double-blind, parallel study. J Am Acad Dermatol. 1998;38(4): S17-S23.

57. Mills $\mathrm{OH} \mathrm{Jr}$, Berger RS. Irritation potential of a new topical tretinoin formulation and a commercially-available tretinoin formulation as measured by patch testing in human subjects. J Am Acad Dermatol. 1998;38(4):S11-S16.

58. Rhein L, Chaudhuri B, Jivani N, Fares H, Davis A. Targeted delivery of salicylic acid from acne treatment products into and through skin: role of solution and ingredient properties and relationships to irritation. J Cosmet Sci. 2004;55(1):65-80.

59. Quigley JW, Bucks DA. Reduced skin irritation with tretinoin containing polyolprepolymer-2, a new topical tretinoin delivery system: a summary of preclinical and clinical investigations. J Am Acad Dermatol. 1998; 38(4):S5-S10.

60. Skov MJ, Quigley JW, Bucks DA. Topical delivery system for tretinoin: research and clinical implications. J Pharm Sci. 1997;86(10): 1138-1143.

61. Del Rosso JQ. The role of the vehicle in combination acne therapy. Cutis. 2005;76(2 Supp1):S15-S18.

62. Orentreich N, Durr NP. The natural evolution of comedones into inflammatory papules and pustules. J Invest Dermatol. 1974;62: 316-320 
63. Korting HC, Lukacs A, Vogt N, Urban J, Ehret W, Ruckdeschel G. Influence of the $\mathrm{pH}$-value on the growth of Staphylococcus epidermidis, Staphylococcus aureus and Propionibacterium acnes in continuous culture. Zentralbl Hyg Umweltmed. 1992;193(1):78-90.

64. Korting HC, Braun-Falco O. The effect of detergents on skin $\mathrm{pH}$ and its consequences. Clin Dermatol. 1996;14(1):23-27.

65. Greenman J, Holland KT, Cunliffe WJ. Effects of $\mathrm{pH}$ on biomass, maximum specific growth rate and extracellular enzyme production by three species of cutaneous propionibacteria grown in continuous culture. J Gen Microbiol. 1983;129(5):1301-1307.

66. Korting HC, Bau A, Baldauf P. pH-Abhängigkeit des Wachstumsverhaltens von Staphylococcus aureus und Propionibacterium acnes: Indikationen einer In-vitro-Studie für den optimalen $\mathrm{pH}$-Wert von Hautwaschmitteln [pH-dependence of the growth of Staphylococcus aureus and Propionibacterium acnes: in vitro study to evaluate the optimum pH of skin detergents]. Ärztl Kosmetol. 1987;17:41-53.
67. Kjeldstad B, Johnsson A, Sandberg S. Influence of $\mathrm{pH}$ on porphyrin production in Propionibacterium acnes. Arch Dermatol Res. 1984;276(6): 396-400.

68. Faccioli F. Evaluation of Microbial Retardation Activity of Farmaka Acne Cream Compared to Commercial Topical Formulation of Benzoyl Peroxide 5\%. Milan; 2013.

69. Leone G. Evaluation of cutaneous tolerance to Kouriles acne during sun exposure. Giorn It Dermat Venereol. 2010;145(1):7-9.

\section{Publish your work in this journal}

Clinical, Cosmetic and Investigational Dermatology is an international, peer-reviewed, open access, online journal that focuses on the latest clinical and experimental research in all aspects of skin disease and cosmetic interventions. All areas of dermatology will be covered; contributions will be welcomed from all clinicians and basic science researchers globally. This journal is indexed on CAS. The manuscript management system is completely online and includes a very quick and fair peer-review system, which is all easy to use. Visit http://www.dovepress.com/testimonials.php to read real quotes from published authors.

Submit your manuscript here: http://www.dovepress.com/clinical-cosmetic-and-investigational-dermatology-journal 